\title{
A ReVoluÇão do PRESEnte
}

\author{
Tania Mara Galli Fonseca ${ }^{\star}$, Selda Engelman ${ }^{\star}$ \\ e Patrícia Gomes Kirs ${ }^{\star \star \star}$
}

\begin{abstract}
RESUMO
Enfoca-se a construção do presente perguntando o que se passa na atualidade a partir de Foucault. Privilegia-se a perspectiva que positiva a capacidade de critica que atravessa o nosso tempo. Foca-se não os empreendimentos revolucionários em si, mas a cartografia dos traços de entusiasmo pelo porvir que sustenta a construção de devires desenhados nas práticas cotidianas dos sujeitos. Visa-se o plano ético de existir, mostrando a vontade de revolução contra o que nos torna fracos, a vontade de poder que se dirige como crítica ao próprio presente, manifestando-se como enunciação coletiva que as práticas organizam e produzem na superficie dos rostos.
\end{abstract}

Palavras-chave: Atualidade. História. Revolução. Devir.

\section{The REVOLUtion OF THE PRESENT}

\begin{abstract}
The text concerns the construction of the present from the question: what we can depict from reality since Foucault. We adopt the perspective that stresses the capacity of criticism and problematics that belong to our time. It attracts our attention not to the revolutionary works, but to a cartography of signs of enthusiasm for the virtuality that supports the construction of possibilities drawn into the daily praxis of the subjects. It is about directing the view to the ethics of existence, showing the desire for revolution against what weakens us, the desire of power that translates into criticism and fights the present, displaying the collective enunciation that practices organizes and produces on the surface of faces.
\end{abstract}

Keywords: Actuality. History. Revolution.

^ Professora do Programa de Pós-Graduação em Psicologia Social e Institucional do Instituto de Psicologia da UFRGS Rua Ramiro Barcelos, 2600, sala 13 - térreo - Instituto de Psicologia UFRGS.

E-mail: tfornseca@psico.ufrgs.br

$\star \star$ Mestre em Psicologia Social e Institucional UFRGS. E-mail: selda@terra.com.br

$\star \star \star$ Mestre em Psicologia Social e Institucional UFRG. E-mail:pgomes.voy@terra.com.br 


\section{I - AUFKL ÄRUNG E REVOLUÇÃo}

Vamos abrir com o que está transbordando...

Experimentamos um "excesso de contemporâneo", como nos aponta David Le Breton (2003). Por um lado, a modernidade líquida de Baumann (2001), na qual os sólidos se liquefazem, as instituições se desmaterializam, derrubam-se os muros, as crenças e as tradições. A nova ordem é de mutação e mobilidade, flexibilidade e velocidade. O novo tempo é o do efêmero e da proliferação das minorias que podem como nos 11 de setembro, implodir enormes materialidades carregadas de certezas e símbolos de macropoderes. Os pequenos vêm à tona, semeando a incerteza e ressentindo antigas dores. Dá a ver, em rede mundial, quase beirando a ficção, o caráter liquefeito do Império. Por outro lado, observamos, hoje, empreendimentos tecnocientíficos dos mais inéditos que têm um interesse no futuro e naquilo que se refere ao cotidiano, principalmente quando o projeto é eliminar ou corrigir o corpo humano (LE BRETON, 2003, p.15). Este se torna território de experimentação da alteração do si, passa a ser concebido como rascunho, opondo-se ao próprio sujeito. Suas fronteiras - que constituem os limites do si, despedaçam-se e semeiam a confusão. Nas instituições, são as próprias edificações enquanto modo de especializar o tempo, que se obsoletizam, deitando por terra o conjunto de concepções e ideais em nome dos quais foram erigidas.

Tais novas configurações e mutações podem vir a ser confundidas com reviravoltas e rupturas, mas, aqui, estamos frente a um enigma. Um corpo que malha um corpo que cumpre com a sua dieta, um corpo firme de silicone e paralisado pelo botóx, que sente a picada do body piercing e que cumpre com as obrigações do orgasmo "viagra", e com a alegria "prozac" não parece cheio de força e vigor para o "perfeito"? Uma instituição que se desmaterializa, deixando ver o fracasso da razão que a concebeu, não parece fato alvissareiro para a liberação de potências e invenção de novos mundos? Talvez, quem sabe, mesmo de um outro humano?

Quando estamos a falar na construção do presente, quando nos pomos a pensar em estratégias de resistência e criação que venham auxiliar na invenção de novos mundos para existir e novas formas de vida para viver não podemos deixar de olhar ao nosso redor para observar e registrar algo daquilo que nos é contemporâneo e que, paradoxalmente, se coloca como limite e como possibilidade de superação e ultrapassamento. Sim, nosso ponto de partida é o aqui - agora (espaçotempo) em que estamos mergulhados, e o nosso olhar não recai sobre as pontas do tempo - lá e então - fazendo-nos recuar em busca de origens passadas ou de futuros imaginários. Não nos move o ímpeto de classificar os fatos da história segundo o eixo de dois pólos: o da antiguidade e o da modernidade, o que torna descabidas as questões que procuram saber se vivemos em um período de decadência ou de progresso em relação aos nossos antepassados. Atolados no tempo, habitamos o ponto que se pode chamar meio, "intermezzo", lugar de onde partem nossas operações de combate e manobras de exploração. Nossos modos e nossa substância existem como efeitos finitos da ilimitada potencialidade formal da vida. 
Como Michel Foucault (1984) em “O que é o Iluminismo?" indagamos, então: "Qual é a minha atualidade? Qual é o sentido desta atualidade? E que é que eu faço quando falo desta atualidade?".

Nosso aqui - agora se coloca como expressão do acontecimento que nos envolve e nossa atualidade pode vir a ser definida por nossa condição de problematizar a Aufklärung ${ }^{1}$ de nosso tempo, aqui tomada como um período que formula sua própria divisa, seu próprio preceito e que diz o que ele tem a fazer, tanto em relação à história do pensamento, como em relação ao seu presente e às formas de conhecimento, de saber, de ignorância, de ilusão nas quais ele sabe reconhecer sua situação histórica.

Segundo esta perspectiva, buscar saber se há um progresso constante para o gênero humano corresponde a determinar se existe uma causa possível deste progresso, liberar um certo acontecimento que mostra que a causa age em realidade. E preciso, pois, isolar na trama da história, um acontecimento que terá valor de signo da existência de uma causa permanente que, por toda a história, guiou os homens no caminho do progresso. Vejamos, ainda no texto acima referido, nas palavras de Foucault (1984) a resposta de Kant ao questionamento: "Há em torno de nós um acontecimento que seria rememorativo, demonstrativo e prognóstico de um progresso permanente que arrasta o gênero humano em sua totalidade?".

Não esperem, diz Kant, que este acontecimento consista em
grandes gestos ou crimes importantes cometidos pelos
homens, após o que, o que era grande entre os homens se
tornou pequeno, ou o que era pequeno se tornou grande, nem
em edifícios antigos e brilhantes que desapareceriam como
que por mágica enquanto que em seus lugares surgiriam outros
vindos das profundidades da terra. Não, nada disso. [...]
Prestem atenção, não é nos grandes acontecimentos que
devemos procurar o signo rememorativo, demonstrativo e
prognóstico do progresso; é em acontecimentos muito menos
grandiosos muito menos perceptíveis. (FOUCAULT, 1984,
p. 107-108)

Vimos, assim, desde a ótica destes filósofos, que o que é significativo e pode operar como signo do progresso, não são os feitos e dramas revolucionários. O que é significativo é a maneira pela qual a Revolução é acolhida pelos que não participam dela ativamente, mas que a consideram que a assistem e que, para melhor ou para pior, se deixam arrastar por ela: o que é significativo é "o que se passa na cabeça dos que não a fazem ou, em todo caso, que não são seus atores principais. O entusiasmo pela Revolução é signo, segundo Kant, de uma disposição moral da humanidade" (FOUCAULT, 1984, p.109) e a Revolução, como lugar de entusiasmo e de revelação de uma disposição humana para progredir, é um acontecimento cuja existência atesta uma virtualidade permanente e que não pode ser esquecida, uma vez que mais do que preservar seus feitos e deles fazer modelos, o que nos interessa é saber o que é preciso fazer desta vontade de revolução que é outra coisa que o empreendimento revolucionário. 
Podemos, daqui, já vislumbrar que a problemática do presente não concerne exclusivamente ao domínio racional da Aufklärung e do estado de coisas e enunciados dela decorrentes. Há uma outra face, a da Revolução que também lhe concerne e que se expressa como um combate contra o presente em favor de um futuro que virá. Uma espécie de fracasso instaurado no seio da racionalidade vigente, algo da ordem do extemporâneo que se coloca na própria atualidade do mundo e dos sujeitos, assinalando-se como um eternamente futuro cravado na carne do presente, conferindo-lhe movimentos vertiginosos, colocando-nos como artesãos de uma interminável escrita que ao mesmo tempo fala de nós e de nosso mundo.

Se as forças que nos rodeiam e nos impelem as velocidades incríveis ainda não estão claras, se o presente é perturbador e exige uma atenção redobrada, como nos diz Pelbart (2000), temos razões para alçar-nos com mais garra à altura desse desafio. Como diz Deleuze, estar à altura do que nos acontece eis a ética essencial.

É desta forma, que problematizar a questão do presente nos remete a colocálo sob o prisma da crítica e da crise não com vistas a destruí-lo, mas a explorarlhe as virtualidades imanentes, liberar-lhe o tempo como potência de duração e diferenciação. Introduzir no balanço do vai-e-vem de Cronos, algo que também não passa que se faz daquilo que é desfeito e que faz proliferar a vida ali mesmo onde a morte é mais violenta e profunda, pode apontar para a rostificação do mundo e dos sujeitos não mais a partir de fôrmas-modelo pré-existentes e universais. Rostificar do mesmo modo como se esculpe formas na areia, cujos contornos se evadem e movem a cada vibração molecular de grãos imperceptíveis; utilizar e buscar as linhas liberadas de formas já significadas, rupturas asignificantes, a-subjetivas, impessoais, dispostas a todas as núpcias e conjugações em prol da produção autopoiética dos corpos. Problematizar a questão do presente invoca, pois, poder focá-lo na perspectiva de sua própria invenção, uma vez que não se trata de conferir-lhe inspiração e entusiasmo a partir de dados pré-existentes e sim de imprimir-lhe uma disposição para o progresso a partir daquilo que está por vir e cuja existência se entrelaça a um agenciamento coletivo ao qual podemos querer pertencer.

Estar à altura do que nos acontece, como acima referido, se coloca vinculado à competência ética que implica no progressivo conhecimento da virtualidade do si - mesmo, como nos explica Francisco Varela (1995), envolvendo uma espécie de aprendizagem que se nutre da própria capacidade de desaprender e do amor ao futuro por vir. Aprender inventivamente não se refere apenas a querer outra coisa, a ter vontade de revolução; significa a produção de estratégias concretas de resistência e bifurcação em relação às formas atualizadas, o que se revela através de ações corporificadas e imediatas, cognição encarnada que não decorre de regras abstratas, uma vez que a ação ética emerge não como representação de um código de regras morais, mas como problema que implica em uma disposição para agir de modo imediato, pertencendo, portanto, ao domínio do corpo e dos afectos. Da mesma forma, aprender inventivamente não pressu- 
põe o direcionamento da ação para a resolução de problemas. Relaciona-se ao índice de transversalização que o corpo suporta e diz respeito às relações de um dentro com o Fora, à abertura do corpo para a diferença, para a perturbação de seu estado estável em direção ao diferir de si mesmo, desdobrando suas potências autopoiéticas. Podemos perceber, neste ponto, que o que passa a ser significativo na história do presente não é propriamente os feitos de um passado remoto ou recente, e sim o seu poder de permanecer afetando aqueles que assistem e acompanham as reviravoltas no até então estabelecido, poder de fazer duração próprio dos acontecimentos intempestivos e inventivos. O que é significativo para o nosso interesse, são as múltiplas formas através do qual o acontecimento revela sua potência de fabricação de mundos e homens através da dupla dinâmica, repetição-diferença, na qual o que retorna é sempre o outro. Assim, as derivas e ressonâncias produzidas no encontro com os corpos, podem nos indicar cada sujeito, como um terminal da imensa rede de afecções e contágio na qual inscreve sua existência. Falamos, aqui, de uma Revolução Molecular, cuja expressão em geral pode ser dada através de feições ainda informes, não instituídas e significadas, ainda inauditas e imperceptíveis. Falamos de um processo de molecularização, de despersonalização, de antagonismo à soberania do eu e de suas referências identitárias, potências do extra-ser que se encontram cravadas na carne do ser, de cuja existência apenas podemos acessar sua manifestação em formas, sendo elas próprias fugidias, aceleradas, nômades, não se deixando nunca resolver, decifrar ou expurgar. Forças nômades que compõem máquinas de guerra, forças de traição e de fazer fracassar aquilo que o clarão da razão de cada época nos apontou como verdadeiro, bom, justo e belo.

Em David Lapoujade, temos a oportunidade de continuar nosso raciocínio quando lemos: “Tudo se passa como se ele 'o corpo' não pudesse mais agir, não pudesse mais responder ao ato da forma, como se o agente não tivesse mais controle sobre ele. Os corpos não se formam mais, mas cede progressivamente a toda sorte de deformações. "(LAPOUJADE, 2002, p. 82) Também reafirmando a dominação contemporânea dos corpos e suas múltiplas ilusões, Deleuze (1997) nos propõe a noção de "gorda saúde dominante" que, ao devorar, expele tudo, e que revigora a própria forma com um estado de não resistência assumindo um quase nada, ou seja, agregando a forma homogênea e macro em sua existência. O que aqui se encontra colocado é a posição de crítica à perspectiva de saúde mental que busca explicar a subjetivação como efeito da ação de adaptação do corpo a um mundo dado e pré-existente, do qual o sujeito deve ser reflexo. Identificações com valores e figuras pré-moldados, formatados e homogeneizados por interesses globalizantes e universalizantes, que engolfam e prendem na massa indiferenciada as potências da diferença e dos desvios. Gorda saúde dominante que, em nome da filiação e inclusão social, busca absorver e neutralizar as potencialidades autopoiéticas dos corpos, colocando-as no caldeirão de um presente sem passado, onde pretende forjar misturas sem memória, sem tempo, sem duração, instantâneas e imediatamente prontas para o consumo e para a obsolescência. A velocidade aqui se reflete na própria desrealização do feito, em sua consumação e devoramento. 
Para os autores acima citados, a problemática da resistência situar-se-ia exatamente no ponto em que o corpo, disposto a abrir-se para sair de si, deixar-se perturbar para produzir-se como multiplicidade, para habitar fronteiras para além do humano, torna-se fragilizado pelos sucessivos desfazimementos, desapegado de certezas e crenças, moribundo e embrionário, o que pode vir a nos confrontar a uma "surdez que é uma audição, uma cegueira que é uma vidência, um torpor que é uma sensibilidade exacerbada, uma apatia que é puro pathos, uma fragilidade que é indício de uma vitalidade superior". O que é que o corpo não agüenta mais? Ele não agüenta mais tudo o que o coage por fora e por dentro, não agüenta o adestramento a que está submetido historicamente e também a culpabilização, a patologizaação do sofrimento, a insensibilização e sua própria negação. Um corpo não cessa de ser submetido aos encontros; ele diz respeito às afecções com a alteridade que o atinge, da multidão de estímulos e excitações que cabe a ele selecionar, evitar, escolher, acolher...

Para mais e melhor, torna-se necessária a atenção às excitações que o circundam, sendo de sua competência a capacidade em evitar a violência que o destruiria de vez. Se considerarmos que o corpo não é definível como unidade psico-física, sendo um ser de consciência e de inconsciência, conforme palavras de José Gil², podemos pensá-lo como em estado de permanente produção, que é, por sua promovida primeiramente pelo encontro com outros corpos. Assim, o corpo não nos é dado. Devemos torná-lo nosso, instituí-lo em nossos códigos de significação e valores. Neste sentido, um corpo não é nada, é portador de uma certa impotência da qual, contudo, pode extrair a potência superior de inventar-se. Tratamos, aqui, "de um querer viver obstinado, cabeçudo, indomável, diferente de qualquer vida orgânica".

Não seria este o sentido que poderíamos dar ao desejo? Transbordamento, excesso, poderosa vitalidade não orgânica, que completa a força com a força e enriquece aquilo de que se apossa. Vida, puro acontecimento, impessoal, singular, neutro, para além do bem e do mal, uma espécie de "beatitude", diz Deleuze. Corpos que falam de uma forma de vida que é sem forma, sem sede de forma, sem sede de verdade, sem sede de julgar e ser julgado.

\section{II - A MUltidẽo E O DeVIR ZAPATA}

Michel Foucault mencionou, pela primeira vez, o termo biopolítico, em uma conferência intitulada: "O Nascimento da Medicina Social", com as seguintes palavras: "O corpo é uma realidade bio-política” (FOUCAULT, 1979, p. 82). É uma menção à medicalização do corpo no contemporâneo, entendido como objeto do poder, e aliado com uma estratégia da Medicina, que passa a controlá-lo e gerí-lo. Na verdade, é o controle sobre a vida.

A vida, principalmente desde a Revolução Industrial, passou a ser o lugar comum. Todos se sentem à vontade para falar em nome da vida, todos a defendem desde os discursos médicos, psiquiátricos, políticos, filosóficos até as práticas dos especialistas que se ocupam da manipulação genética e dos políticos que empreendem guerras planetárias. Quando todos invocam a mesma questão, em direções 
e domínios diferentes, isso deveria ser um sinal de alerta de que a vida tornou-se um campo de batalha, pois, ao mesmo tempo em que uns invocam a defesa da vida e deploram que a mesma seja manipulada, outros, com insistência, justificam, em seu nome, a manipulação cada vez mais evasiva dos corpos.

Delineando-se o campo de batalha no qual a vida é disputada pelo poder, ela passa a dispor o próprio corpo como capital vital, uma certa força de valoração que oportunamente se associa a outras forças, cooperando e se expandindo. Com isto, urge a necessidade da criação de dispositivos que potencializem a emergência de coletivos sociais, da construção de territórios de propagação da vida e que esta possa desdobrar-se ilimitadamente.

A questão do coletivo remete-nos ao conceito de multidão de Paulo Virno (2003) que o propõe em dois sentidos: o sujeito como multidão e os agenciamentos desses sujeitos como multitude.

Espinosa atribui à multidão uma pluralidade que persiste como tal no espaço público, na ação coletiva, sem converger em "um", sem evaporar-se em um movimento centrípeto. De acordo com Virno, para Hobbes a multidão seria o contrário de povo, pois este se desloca do estado natural que precede a instituição do corpo político e busca a convergência no "um", no Estado, na soberania representativa. A multidão teria, então, um sentido negativo, de oposição e polaridade, sendo contraposta ao povo, à unidade política do Estado. Trata-se, aqui, de considerar um tempo social em que as esferas pública e privada se encontravam separadas e delimitadas, assim como vigia a separação da vida política e da vida privada. Lugares específicos por sua vez também diferenciavam modos de viver e os dispositivos institucionais, desde a Revolução Industrial, reproduziam um sistema de divisão da experimentação do tempo e do espaço, tais como a Família, a Escola, a Fábrica, o Manicômio, a Prisão, o Exército e o Convento. As distinções entre os modos de ser se faziam conforme as especificidades dessas organizações.

Já na modernidade líquida do contemporâneo, observamos a crise dos dispositivos institucionais específicos, o "embeiçamento" das esferas pública e privada, registrando-se, ainda que o próprio sentido de comunidade se mostre diluído, assim como esvaziadas as tradições e certezas que acompanharam o trajeto de tantas gerações. A produção social, isto é, o conjunto vigente de formas de vida, a atual constelação social, antropológica e ética, toma o lugar do que é chamado comum. A inteligência coletiva abre espaço para esferas públicas não estatais, tal como a WEB, por exemplo. Assim é que, na atualidade, o conceito de multidão passa por esse coletivo, reapropriando-se de um regime-saber antes congelado no aparato do Estado e das instituições e, transformando-o, colocando-o em permanente movimento.

Em Virno, também encontramos o conceito de multidão como subjetividade. Para o autor, a pluralidade, os muitos, a multidão consiste em uma rede de indivíduos, sendo que o ponto decisivo é considerar a singularidade como um ponto de chegada e não um ponto de partida. Os muitos são os resultados complexos de uma diferenciação progressiva, o resultado de um processo, o processo de individuação. $\mathrm{O}$ que precede a individuação é uma realidade pré-individual, algo 
comum, universal, indiferenciado. Este comum esta realidade, poderia ser o fundo biológico da espécie, tais como os órgãos sensoriais, aparato motor e prestações perceptivas. Este universal percepção / sensação, não é descrito mediante a primeira pessoa do singular, pois não é nunca um "eu" individual que sente, vê, toca, mas a espécie como tal. Falamos se vê, se toca se sente. Outra realidade universal é a língua, que é de todos e não é de ninguém. No interior da fala se enraíza o processo de individuação, no qual o sujeito passa da linguagem como experiência pública à linguagem como singularizante. Por último, teríamos como pré-individual a relação de produção dominante, o conjunto das forças produtivas, conforme já observado que seriam o intelecto geral e os aspectos lingüísticos. A multidão leva em suas costas toda esta realidade pré-individual.

Ainda em Virno, encontramos Simodon, para quem a individuação não é completa, o pré-individual não se traduz todo em singularidade, sendo que o sujeito consiste na trama de elementos pré-individuais e aspectos individuados. Uma teia na qual o sujeito pode ser um composto "eu", mas também um composto "se".

Observa-se que aqui o Campo de Batalha é outro. Não mais a vida como campo de batalha do poder, na biopolítica de Foucault. O próprio sujeito é um campo de batalha, pois o eu individuado convive com o "se". Os aspectos préindividuais provocam, questionam a individuação fazendo com que esta se mostre como um resultado precário, sempre reversível. Por outro lado é o "eu" que parece reduzir a si todos os aspectos pré-individuais de nossa experiência. Delineiam-se o corpo paradoxal, organismo e CSO (Corpo Sem Órgãos) simultaneamente. E essa relação entre pré-individual e individuação é mediada pelos afectos. A produção de afectos intensifica essa relação, a potencializa.

Para Simodon (apud VIRNO, 2003) o coletivo, a experiência coletiva, a vida do grupo pode constituir-se território de uma nova individuação, pois é nesta participação coletiva que o sujeito tem ocasião de individuar e atualizar a quota de realidade pré-individual que leva sempre em si. O coletivo acentua e persegue o processo de individuação, sendo o indivíduo o resultado final do processo.

Para finalizar, a partir das considerações de Cecília Coimbra no texto Estratégias de Resistência e Criação: Ontem, Hoje..., ${ }^{3}$ propomos uma breve menção ao que vamos denominar de Devir Zapata.

Quando o suposto subcomandante Marcos sobe a montanha. Da selva atualizando a utopia zapatista. Cobre o rosto. E sobre seu cavalo e suas costas carrega a potência da multidão. Multidão dos sem terra, sem educação, sem saúde e repletos de gana de ação e vontade de poder. Ao cobrir o rosto não somente carrega seu corpo e faz desaparecer sua face e permitindo visibilizar um sonho instituíste, movimentado pelo desejo de cada um ser aquele cavalheiro nômade que, na exaustão de suas trilhas, faz consistir devirem minoritários.

Esta aura misteriosa de dar passagem ao outro, este fervor zapatista é um duplo na existência, aquela singularidade corajosa que insiste na criação de uma 
ética nascente, não negando as armas para um dia, quem sabe, deslizar no rizoma e não finalizar a metamorfose. Os subcomandantes Marcos, João, Pedro, Antônio não alimentam o final feliz ou o dia emblemático do descanso. São corpos que não agüentam mais.

Sua trilha é uma fotografia do tempo de uma cicatriz, sua materialidade é um rastro de potência que faz com que olhemos para o mundo e possamos nos surpreender com a flexibilidade dos limites do não-lugar.

\section{Nota}

1 Was ist Aufklärung (O que é o Iluminismo), de Immanuel Kant, aqui colocado em análise por Michel Foucault em um contexto de estudo sobre história da filosofia. Para Foucault, o texto não coloca diretamente as questões da origem e do fim, mas posiciona-se de modo discreto, quase lateral, em relação à teleologia imanente ao processo mesmo da história.

2 GIL, José Nuno. Abrir o corpo. Trabalho apresentado no Simpósio Internacional Corpo, Arte e Clínica, promovido pelo PPGPSI/UFRGS, Porto Alegre, abr. 2003.

3 COIMBRA, Cecília. Estratégias de resistência e criação: ontem e hoje... Texto apresentado no XII Encontro Nacional da Abrapso, Porto Alegre, out. 2003

\section{REFERÊNCIAS}

BAUMANN, Z. Modernidade líquida. Rio de Janeiro: J. Zahar, 2001.

BRETON, D. Adeus ao corpo. São Paulo: Papirus, 2003.

COIMBRA, C. Estratégias de resistência e criação: ontem e hoje. Texto apresentado no XII Encontro Nacional da Abrapso, Porto Alegre, out. 2003

DELEUZE, G. Crítica e clínica. São Paulo: Ed. 34, 1997.

FOUCAULT, M. História da sexualidade: o uso dos prazeres. Rio de Janeiro: Graal, 1984. v. II. . Microfisica do poder. Rio de Janeiro: Graal, 1979.

GIL, J. N. Abrir o corpo. Trabalho apresentado no Simpósio Internacional Corpo, Arte e Clínica, promovido pelo PPGPSI/UFRGS, Porto Alegre, abr. 2003.

LAPOUJADE, D. O corpo que não agüenta mais. In: . Nietzsche e Deleuze: que pode o corpo. Rio de Janeiro: Relume - Dumará, 2002.

PELBART, P. Prefácio. In: . Formas de ser e habitara contemporaneidade. Porto Alegre: Ed. UFRGS, 2000.

. Vida capital: ensaios de biopolítica. São Paulo: Iluminuras, 2003.

VARELA, F Sobre a competência ética. Lisboa: Edições 70, 1995.

VIRNO P. Virtuosismo y revolución, la acción política en la era del desencanto. Madrid: Mapas, 2003. 
Tania Mara Galli Fonseca, Selda Engelman e Patrícia Gomes Kirs

Recebido em abril / 2006

Aceito em setembro / 2006 